\title{
HOSPITALIDADE NA CIDADE: AS MANIFESTAÇÕES CULTURAIS COMO USO DO ESPAÇO PÚBLICO
}

\author{
HOSPITALITY IN THE CITY: CULTURAL MANIFESTATIONS AS USE OF \\ PUBLIC SPACE
}

\section{HOSPITALIDAD EN LA CIUDAD: LAS MANIFESTACIONES CULTURALES COMO USO DEL ESPACIO PÚBLICO}

\section{Fábio Molinari Bitelli}

Doutorando do Programa de Pós-graduação em Ciências da Integração da América Latina (PROLAM) da Universidade de São Paulo (USP)

Professor de Gastronomia no Centro Universitário SENAC em São Paulo.

fabiombitelli@usp.br

Orcid: https://orcid.org/0000-0001-8453-0567

\section{Sênia Regina Bastos}

Doutora em História pela Pontifícia Universidade Católica de São Paulo

Professora da Pós-Graduação Mestrado e Doutorado em Hospitalidade Universidade Anhembi Morumbi

srbastos@anhembi.br

Orcid: https://orcid.org/0000-0001-9978-1836

Data de submissão:07/11/2017 - Data de aceite:18/06/2018

RESUMO: Bairro inicialmente formado por negros e imigrantes (predominantemente italianos), o Bexiga, localizado na região central da cidade de São Paulo, está inserido no distrito Bela Vista e tem enraizada no uso de seu espaço público a cultura festiva desses grupos formadores. Nesse território, manifestações culturais vêm surgindo desde 1926, algumas permanecem e contribuem como atrativo turístico, de lazer e de sociabilidade. Com o objetivo de entender o bairro sob os aspectos da hospitalidade urbana, a pesquisa concentrou-se na busca de categorias para análise dessas manifestações culturais inventariadas e compreendidas como corpus desse artigo. O referencial teórico sobre espaço público e hospitalidade urbana, realizado por meio de levantamento bibliográfico, fundamentou as categorias de acessibilidade, identidade, legibilidade, cidadania e vivência, posteriormente avaliadas com base na observação participante, e contribuiu para o desenvolvimento do estudo. Como resultado, as manifestações apresentaram na prática, em menor ou maior grau, o alcance dos conceitos relacionados às categorias em questão, convergindo à hospitalidade na cidade. Espera-se que a apresentação de tais categorias contribua para pesquisas futuras, como instrumento prático de aplicação, objetivando a identificação da hospitalidade urbana nos estudos do espaço público.

PALAVRAS-CHAVE: Hospitalidade urbana. Categorias de análise. Espaço público. Manifestações culturais. 
ABSTRACT: Initially settled by Blacks and immigrants (predominantly Italians), the neighborhood of Bexiga, in downtown São Paulo, is located within the district of Bela Vista. The festive culture of these early inhabitants is rooted in the use of its public spaces. These cultural manifestations have been appearing since 1926; some still remain, providing tourist attractions, leisure and sociability. In order to understand the neighborhood in terms of the aspects of urban hospitality, this research looks for categories for analyzing these culture manifestations, which are listed and understood as the corpus of this article. The theoretical framework on public space and urban hospitality, derived from a bibliographical survey, was based on the categories of accessibility, identity, readability, citizenship and experience, together with participant observation, and contributed to the development of the study. As a result, these manifestations, to a lesser or greater extent, fulfil the concepts related to the categories in question, increasing the hospitality in the city. It is hoped that the presentation of these categories will contribute to future research, as a tool for practical application, aiming at the identification of urban hospitality in studies on public space.

KEYWORDS: Urban hospitality. Analysis categories. Public space. Cultural manifestations.

RESUMEN: El barrio inicialmente formado por negros e inmigrantes (predominantemente italianos), el Bexiga, ubicado en la región central de la ciudad de São Paulo está insertado en el distrito Bela Vista y se ha enraizado en el uso de su espacio público la cultura festiva de esos grupos formadores. Las manifestaciones culturales vienen surgiendo desde 1926, algunas permanecen y contribuyen como atractivo turístico, de ocio y de sociabilidad. Con el objetivo de entender el barrio bajo los aspectos de la hospitalidad urbana, la investigación se concentró en la búsqueda de categorías para el análisis de esas manifestaciones culturales inventariadas y comprendidas como corpus de este artículo. El referencial teórico sobre espacio público y hospitalidad urbana, logrado por medio de levantamiento bibliográfico, fundamentó las categorías de accesibilidad, identidad, legibilidad, ciudadanía y vivencia, qué asociadas a la observación participante, contribuyó al desarrollo del estudio. Como resultado, las manifestaciones presentaron en la práctica, en menor o mayor grado, el alcance de los conceptos relacionados a las categorías presentadas, convergiendo a la hospitalidad en la ciudad. Se espera que la presentación de tales categorías contribuya a investigaciones futuras, como matriz práctica de aplicación, objetivando la identificación de la hospitalidad urbana en los estudios del espacio público.

PALABRAS CLAVE: Hospitalidad urbana. Categorías de análisis. Espacio público. Manifestaciones culturales.

\section{INTRODUÇÃO}

Marcadamente ocupado por negros, imigrantes (sobretudo italianos) e migrantes nordestinos, inscrito no distrito da Bela Vista, o Bexiga $^{1}$ ainda apresenta características iniciais que datam dos primeiros anos do século XX e que seguem contextualizadas à realidade urbana da cidade de São Paulo, que naquele momento despontava para a metrópole que é hoje.

Apesar das inúmeras transformações, que vão da mudança da denominação às alterações viárias, o bairro tenta conservar sua identificação como Bexiga ${ }^{2}$ e, na medida do possível, o seu patrimônio arquitetônico, mas inegavelmente mantém viva a sua diversidade étnica, tradição festiva e cultural a partir de inúmeras manifestações que ocorrem dentro de seus limites.

\footnotetext{
1 Também conhecido como Bixiga (com a vogal “i”), teve o nome alterado para Bela Vista em 1910.

2 Inserido no distrito Bela Vista, não existe uma demarcação oficial do Bexiga. Integra a subprefeitura da Sé juntamente com outros sete distritos: Sé, República, Bom Retiro, Cambuci, Consolação, Liberdade e Santa Cecília.
}

Tombado pela municipalidade em razão de seu patrimônio edificado a partir de $2002^{3}$, concentra a maior densidade demográfica da cidade de São Paulo, com 267 habitantes $/ \mathrm{m}^{2}$ (IBGE, 2010). A vitalidade do espaço público, quer como "extensão" do espaço doméstico (decorrente de sua característica majoritariamente horizontal e uso como moradia acortiçada, informal e de baixa renda), quer como local privilegiado para a realização de atividades culturais, econômicos e sociais, diferencia-o no contexto paulistano.

Um total de dez manifestações culturais, identificadas a partir da pesquisa de campo, são tratadas como corpus dessa pesquisa, que ao se destacarem como atrativo e ocupação dessa área, seguem analisadas como práticas da hospitalidade urbana. Essas saídas a campo foram realizadas

3 O bairro foi tombado pelo Conselho Municipal de Preservação do Patrimônio Histórico, Cultural e Ambiental da Cidade de São Paulo (CONPRESP). Resolução no 22/2002. Disponível em: http://www. prefeitura.sp.gov.br/cidade/upload/49c99_22_T Bairro_da_Bela_Vista.pdf 
durante os anos de 2015 e $2016^{4}$ para a identificação das manifestações culturais que ocorrem no seu espaço público compreendido no interior do bairro.

A prática metodológica empregada nesse estudo foi a observação participante apoiada no referencial teórico sobre hospitalidade urbana e espaço público. Fundamental foi identificar categorias para a análise e discussão das manifestações inventariadas.

A partir dos estudos de Grinover (2009, 2013, 2016), Bell (2007) e Raffestin (2008), foi possível contextualizar os temas que justificassem o conceito da hospitalidade urbana e de algumas categorias predefinidas. Diante da impossibilidade de desassociar o espaço público da temática, buscaramse estudos em autores como Nogueira (2015) e Calliari (2016), que centralizaram suas pesquisas na metrópole de São Paulo contemporânea. Destacase a contribuição desse último na fundamentação de uma das categorias selecionadas.

Ao compor e analisar o referencial teórico, optou-se por cinco categorias: (1) acessibilidade, (2) identidade, (3) legibilidade, (4) cidadania e (5) vivência. A escolha justifica-se pela recorrência nas obras consultadas, aproximação e pertinência dos conceitos levantados de cada uma delas. Posto isso, o corpus da pesquisa foi analisado e classificado de acordo com a escala de valores: igual a 1 (um) para Não Atende; igual a 2 (dois) para Atende Parcialmente; e 3 (três) para Atende Totalmente.

Foram apreciados os resultados obtidos de forma que a discussão comtemplasse as avaliações inferiores ao valor 3 (três) - logo, aqueles que não atendiam totalmente ao conceito definidos nas categorias -, permitindo assim justificativa(s) para a avaliação e composição dos resultados. Tais manifestações culturais são para a cidade de São Paulo, seja pelo alcance de público, permanência ou potencialidade na promoção da sociabilidade, exemplos de uso do espaço público urbano e de hospitalidade.

Esse conjunto de manifestações tratado como corpus dessa pesquisa serviu de objeto para aplicação e análise, categorias que aplicadas em conjunto podem ser referenciadas como instrumento metodológico para classificação do conceito de hospitalidade urbana, que possui como lócus (ou área da pesquisa) o espaço público da cidade, fato que sugere sua utilização em estudos futuros.

4 A pesquisa integra a dissertação de mestrado do Programa de Pós-Graduação, defendida em 2017.

\section{HOSPITALIDADE URBANA E CATEGORIAS DE ANÁLISE}

À hospitalidade interessa a proximidade e o encontro e este é talvez o seu principal significado, considerando a latente presença da globalização e do individualismo. Em sua definição, concentramse os domínios classificados e apresentados por Lashley (2004, p. 5-6), utilizando as instâncias sociais, privadas e comerciais da hospitalidade, todas estão relacionadas aos atos da cena hospitaleira de recepcionar, hospedar, alimentar e entreter pessoas nos contextos doméstico, profissional ou público (Camargo, 2003, p. 19).

Cada domínio representa uma possível oferta, independente ou conjunta, de hospitalidade: o domínio social considera os cenários sociais em que a hospitalidade e os atos ligados à ela ocorrem, esse espaço geralmente é público; o domínio privado considera o âmbito das questões associadas à oferta doméstica da cena hospitaleira, assim como leva em consideração o impacto do relacionamento entre anfitrião e hóspede; e o domínio comercial diz respeito à oferta de hospitalidade como atividade econômica e inclui as atividades dos setores tanto privado quanto público. Concentrou-se aqui no domínio social, que apoiado no espaço público da cidade tem como potencial a observação e a análise da hospitalidade urbana.

A hospitalidade encontra cenário na cidade como emissora/receptora de pessoas de diferentes países a partir da Idade Moderna. Marcada pelo rápido crescimento das urbes, amparada então no direito de ir e vir incondicional ou até em casos de nações com tratados específicos, a hospitalidade urbana veio progressivamente tomando o espaço em detrimento da hospitalidade no ambiente doméstico (que até o momento histórico funcionava como a única forma de recepção do estranho/ estrangeiro/forasteiro): "De caráter duvidoso, o estrangeiro é, antes de tudo, um estranho e tal como a análise etimológica da palavra remete, tanto pode ser um hóspede quanto um inimigo. Desse aspecto resulta a característica reservada com que se o acolhe." (Bastos, Rameh \& Bitelli, 2016, p. 3)

Bell (2007) debruçou-se sobre as discussões acerca dos "espaços e geografias" na cidade contemporânea e como explorá-los nas relações entre as práticas de hospitalidade no ambiente comercial e processos de regeneração urbana; sugere discussões filosóficas ou teóricas sobre o papel dos 
espaços de hospitalidade no ambiente comercial como produção dos novos padrões de vida urbana e, confrontando essas questões, encontram-se novas formas de compreensão e teorização de cultura e consumo. Sobre os significados, usos e limites das relações hospitaleiras, o autor procura mostrar o potencial produtivo ao apresentar duas formas de pensar a hospitalidade:

[...] podemos chamar de "hospitalidade mundana" aquela que está sendo forjada nos espaços comerciais, como uma parte importante da "cidade hospitaleira" - de produzir uma identidade urbana distinta, centrada na experiência dos espaços de consumo e usada como um dispositivo de promoção de lugar. Essa ideia da cidade hospitaleira tornouse importante para a promoção da regeneração, as cidades pós-industriais se vendendo como espaços de lazer e prazer (Bell, 2007, p. 8 - tradução livre).

A primeira característica socioespacial da hospitalidade é o limite, entre interioridade e exterioridade, entre o antes e o depois, o conhecido e o desconhecido. São limites que geram um duplo sistema de fronteiras: internas, que regulamentam o espaço de recepção, que hóspedes e convidados devem observar; externas, que delimitam espaços autorizados e espaços proibidos, além dos quais o estrangeiro é indesejado (Raffestin, 2008).

Para Derrida (2003), atualmente a reflexão sobre a hospitalidade pressupõe a possibilidade de uma delimitação austera das soleiras ou das fronteiras nas relações entre o familiar e o não familiar, entre o estrangeiro e o não estrangeiro, entre o cidadão e o não cidadão, e destaca o privado e o público. Utilizando como exemplo Argélia e França, ainda (desde 1830) envoltos nas discussões da história do estrangeiro, da cidadania, do futuro das fronteiras, segregando cidadãos: numa parte os de uma segunda zona ou de não cidadãos, evidenciando uma complexidade, uma mobilidade, uma sobreposição que, para o autor, não existe outro exemplo no mundo. Por fim, as discussões teóricas de Derrida (2003) proporcionam uma reflexão para entender a hospitalidade como uma forma de se relacionar, como ética e principalmente como política.

Em tempo, as pesquisas realizadas visando à discussão da hospitalidade urbana se apoiam em conceitos já consolidados da hospitalidade, que evoluem e se adaptam constantemente ao crescimento das cidades e do cotidiano urbano.

Com intuito de identificar referências sobre o tema, foi consultado o Google Acadêmico com a palavra-chave "hospitalidade urbana". A busca apresentou um total de 25 trabalhos, dos quais 12 foram selecionados; a saber: Castro (2002), Grinover (2005; 2006; 2009; 2013), Bastos e Salles (2008), Junqueira e Rejowski (2010), Salles et al. (2010), Ferraz (2013), Severini (2013), Bitencourt e Pinheiro (2014) e Wassal e Salles (2016). Desse resultado optou-se prioritariamente pelas pesquisas de Grinover (2005; 2006; 2009; 2013) e Severini (2013), seleção justificada pela consistência e recorrência da temática nas obras, bem como esses estudos/autores terem sido referenciados nos demais trabalhos. No entanto, outros autores foram agregados, a partir da pesquisa bibliográfica, para contribuição do referencial teórico acerca de outros conceitos.

Do conteúdo, elencaram-se categorias considerando a recorrência dos termos e dos conceitos discutidos pelos autores: acessibilidade, legibilidade, identidade e cidadania (Grinover, 2016) e vivência (Calliari, 2016).

A hospitalidade urbana relaciona-se ao estabelecimento de vínculos do homem com o espaço social, fato que direciona as categorias selecionadas, norteia conceitualmente os caminhos para análise e possibilita tratar as manifestações desenvolvidas no espaço público do Bexiga, em São Paulo, como objetos possíveis de aplicação e análise.

A acessibilidade impõe-se como início natural para problemas e debates sobre sociedades contemporâneas, principalmente nas cidadesmetrópole, devidoà relação direta com a mobilidade urbana, "entendida esta em suas tendências e incidências sobre o ambiente, a morfologia urbana, os modos de vida, a acessibilidade aos lugares" (Grinover, 2016, p. 194). Seu cenário é o espaço público e centraliza o estudo nas práticas sociais que ocorrem nesse meio, o que possibilita certo aprofundamento sobre as interações e as formas de apropriação que ali ocorrem. Raffestin (2008, pp. 174-175) cita o urbanismo como mecanismo da hospitalidade da cidade responsável pelo "arranjo geral das paisagens urbanas e pela organização dos lugares públicos", e utiliza a praça pública "que no ocidente teve papel considerável como lugar hospitaleiro por definição" como um dentre vários 
exemplos possíveis. Questão diretamente atrelada à acessibilidade é o prolongamento da expectativa de vida e, portanto, o envelhecimento da população citadina, fato esse tratado comumente por arquitetos e urbanistas.

A identidade parte do pressuposto que as manifestações culturais criadas pelo homem se firma num espaço e num período determinado de tempo, e que toda a construção patrimonial é uma representação pelos traços e pelas características identitárias, originárias do presente que a idealiza: “[...] o espaço público é importante para a identidade não só do homem urbano como da própria cidade contemporânea" (Calliari, 2016, p. 57). Essas identidades produzem relações de pertencimento, coesão social, reconhecimento individual e promoção da segurança, do conforto e da aceitação: "As identidades fundamentam-se em dados reais e objetivos, recolhidos de traços, hábitos, maneiras de ser e acontecimentos do passado, tais como os lugares e os momentos, isto é, os territórios." (Grinover, 2016, pp. 220-221)

Considera-se a legibilidade como uma forma de "ler" a cidade, de entendê-la, bem como sua relação com o passado e com a memória, a partir das modalidades com que a cultura utiliza a tradição física, a cidade construída, as arquiteturas, os monumentos e a tradição, por meio dos signos, códigos comunicativos, interpretativos, celebrações. Relevância oriunda da capacidade de significar o pertencimento ao passado e de reproduzir a história. Calliari (2016, p. 63) sugere que as particularidades e os detalhes na construção dos espaços da cidade, além de ajudar os transeuntes a se orientarem, aumentam a sensação de pertencimento, logo apresenta-se como um coletivo de formas arquitetônicas e/ou de experiências culturais. A partir da cidade atual, Raffestin (2008, p. 173) valida a existência do que ele chama de hospitalidade "imediata", com a qual o recém-chegado prontamente se depara.

Nas cidades bem identificadas, o estrangeiro se sente acolhido, até bem recebido, ele sabe aonde vai, ele acha o que procura sem perda de tempo, e ele pode se abandonar a passeios e à contemplação sem o risco de se perder. A informação, nesse caso, está ligada ao dom. Oferecer e receber a informação é um mecanismo de hospitalidade (Raffestin, 2008, p. 173 - tradução livre).
Quanto à cidadania, historicamente ser cidadão era ser membro de um corpo mais amplo, pertencer a alguma unidade socioeconômica e cultural, ser identificado com uma nação particular, com seus direitos garantidos pelo Estado correspondente. E de uma maneira mais geral (e atual), ser cidadão é ser portador de direitos e obrigações. $\mathrm{Na}$ abordagem sobre a importância a ser dada ao espaço público, sugerese a discussão sobre o anfitrião urbano, contudo é preciso entender as características desse espaço e a quem pertence, ou seja, capacitá-lo e estimulálo ao exercício da cidadania. Logo, se o espaço da hospitalidade urbana é o espaço público, as relações homem-espaço devem se apropriar e investir em espaços públicos de qualidade, em condições de receber, alojar e entreter turistas e moradores (Severini, 2014).

Outros aspectos podem ser analisados:

[...] a tensão entre cidadania como "status" e cidadania como "identidade" -. Porém, de qualquer forma, há outra dimensão, mais valorizada pela teoria sociológica, mas igualmente implícita na teoria política, que é a ideia de que cidadania é uma identidade compartilhada, como são compartilhados, na ideia de hospitalidade, território, abrigo, alimentação e afeto (Grinover, 2016, pp. 264-265).

Félix, Ipiranga, Câmara e Rodrigues (2008, pp. 337-338) refletem sobre a cidade como um espaço de convívio e de exercício da cidadania, logo como um espaço maior que ultrapassa aquele geográfico demarcado, "a cidade é o espaço no qual se estabelecem as relações de vida e de trabalho. Ao mesmo tempo em que estão definidas, neste contexto, as normas, a distribuição do poder e demais relações que compõem o contexto local", de troca dos aspectos objetivos e subjetivos da vida cotidiana entre os sujeitos, também apoiado na demanda de participação política e de criação/ manutenção identitária. Esses âmbitos evidenciam a busca pela cidadania quando do acesso aos direitos de uso do território/espaço da cidade, outrossim em busca da criação de pertencimento e, mediante as práticas sociais e culturais, de reconhecimento das instituições públicas.

Também como categoria, considerou-se a vivência, pois ao sugerir a experimentação do espaço público em comum com outrem, 
permite que os cidadãos exerçam seus direitos. Por meio da vivência - e isso inclui o estar presente ativo e fisicamente - se constrói nos encontros e nas atividades cotidianas a sensação de pertencimento àquele espaço. Calliari (2016, p. 61) então descortina que essa prática dá sentido ao espaço vivido, tornando-o íntimo, habitável, que desencadeia dois conceitos: o primeiro é a presença de humanidade, pois traz para a escala humana e para a experiência individual "a rua onde crescemos, a pracinha que frequentávamos quando crianças, as pessoas que conhecemos, os encontros que tivemos" e que a experiência coletiva também determina as lembranças e os fatos significativos dessa sociedade, referenciando a prática da sociabilidade; o segundo conceito trata do "espaço como palco da vida", da vida pública, em que se desenvolvem as representações encenadas pelos diferentes personagens, haja vista que a partir da vivência incorpora-se personalidade.

Pertinente então o questionamento: quais as características que o espaço público deve buscar no alcance da hospitalidade urbana? Para esse estudo, as categorias acessibilidade, identidade, legibilidade, cidadania e vivência foram identificadas (em menor ou maior grau) nas manifestações que foram objetos da pesquisa, como possível resposta ao questionamento.

\section{ESPAÇO PÚBLICO NA CIDADE DE SÃO PAULO}

Durante o período de realização da pesquisa, notaram-se grandes avanços no uso do espaço público na cidade de São Paulo, apontando para a (re)apropriação dos moradores, prática que colabora positivamente à hospitalidade na cidade.

Essa é uma tendência também em outras cidades, de acordo com a agência Edelman Significa, que divulgou pesquisa de mercado, produzida com metodologia própria e aplicada nas maiores cidades da Argentina, Brasil, Colômbia e México com objetivo de traçar o perfil dos moradores latino-americanos.

Realizada em 2016, a pesquisa teve o resultado referente à cidade de São Paulo compilado em um material chamado Cultural Connections São Paulo ${ }^{5}$, que segue disponível para consulta pública. Cita, entre os principais resultados, que:

5 Resultado da pesquisa apresentado no formato e-book. Disponível em: https://www.edelman.com.br/ propriedades/edelman-lanca-estudo-inedito-sobretendencias-de-consumo-na-america-latina-2/
As ruas também passaram a ser território não apenas de veículos motorizados, mas de pessoas à procura de encontro, troca e convivência. A Avenida Paulista, um dos principais símbolos da cidade, passou a ser fechada aos domingos para a circulação de carros, ônibus e motos para dar lugar a indivíduos interessados em caminhar ou praticar quaisquer atividades de lazer, esporte e cultura. O projeto "Ruas abertas" inclui principais avenidas de toda a cidade, incluindo também a periferia da cidade. (Edelman, 2016, p. 13).

Depois de um período-teste de um ano, a Avenida Paulista passou a ser fechada permanentemente todos os domingos, nos horários entre $9 \mathrm{~h}$ e $17 \mathrm{~h}$, para exclusiva utilização em favor do lazer e do convívio da população e de turistas. A ação foi fruto do Projeto Ruas Abertas, da Prefeitura Municipal de São Paulo, que também abrange outras áreas da cidade e que discute a decisão mediante consulta pública aos moradores da cidade por intermédio das subprefeituras.

O programa tem como objetivo abrir para pedestres e ciclistas ruas e avenidas de grande relevância no perímetro de 1 a 3 quilômetros, aos domingos e feriados, das 10 às 17 horas, como forma de promover uma melhor ocupação do espaço público e ampliar os espaços de lazer na capital paulista (São Paulo, 2015).

Outro espaço que aos domingos é utilizado para uso público e convívio é o Parque Minhocão, assim foi batizado o elevado Presidente João Goulart ${ }^{6}$, via expressa elevada, inaugurada em 1971 e que faz a ligação leste-oeste da cidade de São Paulo, até então exclusivamente para veículos. Urbano e central, o elevado é fechado para os carros e transformado em parque aos domingos para utilização livre, seu uso ocorre de forma variada, mas com predominância das atividades físicas e de lazer.

Nogueira (2015), em seu estudo que parametrizou o High Line Park em Nova Iorque, Estados Unidos, e o Parque Minhocão em São Paulo, comparou os dois espaços em virtude da semelhança na estrutura - ambos são vias elevadas 6 Seu nome era elevado Costa e Silva. Talvez seja o caso de inserir uma nota. Sugestão: Denominado inicialmente como elevado Costa e Silva, foi edificado durante a gestão municipal de 1969 a 1971, com 3,4 $\mathrm{Km}$ de extensão, conectando o bairro de Perdizes à Praça Roosevelt, no centro. 
e se tornaram símbolo da falta de hospitalidade urbana. O primeiro sofreu revitalização e foi entregue como parque. Atestando a participação pública na decisão, Nogueira (2015, p. 113) cita duas entidades que atuam exclusivamente em favor do futuro da região do Parque Minhocão, "Essa dualidade tem sido intensamente debatida pelos órgãos públicos através de audiências marcadas principalmente por cidadãos pertencentes a duas entidades de representação social com objetivos distintos: Associação Parque Minhocão e Veredas", indicando assim que existe um movimento que valoriza a ocupação desse espaço por parte da população sensivelmente organizada. Os partidários desse movimento buscam justamente a transformação dessa estrutura em parque suspenso e outros advogam em favor da demolição de "um símbolo de urbanismo centralizador, rodoviarista" e que "baseiam-se principalmente na possibilidade de recuperar a imagem da rua" (Calliari, 2016, pp. 180-181). Ambos sugerem fortemente ações que promovem principalmente sua ressignificação.

$\mathrm{Na}$ Europa, outro movimento, chamado social street, que começou em 2013 a partir da iniciativa de um morador de uma pequena rua na cidade de Bologna na Itália, pai de uma criança que não tinha com quem brincar, começou a fixar cartazes na própria rua com o intuito de convocar os moradores ao convívio. De acordo com a reportagem exibida no Programa Globo Repórter no dia 27 de maio de $2016^{7}$, cujo próprio idealizador é entrevistado, em pouco tempo, já eram mais de 70 pessoas convivendo no espaço público e outras relações baseadas em trocas, pequenos serviços de artesãos e movimentos artísticos foram surgindo, agregando visitantes de outras regiões.

Considerando os quatro exemplos citados de ocupação e uso dos espaços da cidade, da rua, público, passa a ser um campo produtivo para análise e estudo da hospitalidade urbana. E o que definiria o espaço público? O fato desse espaço não estar submetido à nenhuma autoridade ou uso privado, destinado à prática social livre e comum, lugar de cidadania, de empatia, de contato com o outro, que favorece as relações de sociabilidade, portanto acessível ao uso comum, com o intuito de minimizar as diferenças, sejam elas quais forem.

O bom espaço público é sugerido por Calliari (2016) como aqueles que atraem frequentadores

7 Vídeo disponível em: http://g1.globo.com/globoreporter/noticia/2016/05/invencao-cria-proximidadeentre-vizinhos-de-rua-em-bologna-na-italia.html. e sejam usados, agregadores de algumas variáveis como: significado, que mediante a vivência transforma o espaço em lugar; legibilidade, que parte do mesmo princípio de Grinover (2016) - o ser humano tem maior facilidade de se relacionar com um espaço se puder compreendê-lo; a cidade como ambiente coletivo é ambiente do outro, da alteridade, logo da diversidade; e escala humana, considerando que o espaço público somente se envolve de sentido quando do próprio uso humano, esse está mais passível de ser utilizado à medida que se aproxima de seu público.

\section{MANIFESTAÇÕES CULTURAIS DO BAIRRO BEXIGA EM SÃO PAULO}

A definição de cultura de Williams (1969) instiga ao debate principalmente em virtude da complexidade do termo. Defende que as questões implicadas na palavra cultura foram oriundas das grandes transformações históricas vinculadas aos termos indústria, democracia, classe e $\operatorname{arte}^{8}$ : "a evolução da palavra cultura dá testemunho de numerosas reações, importantes e continuadas, a essas alterações de vida social, econômica e política e pode ser encarada, em si mesma, como um especial tipo de roteiro, que permite explorar a natureza dessas mesmas alterações" (Williams, 1969, p. 18). Sendo assim, não se limita a apenas um significado e aponta suas transformações:

Anteriormente significara, primordialmente, "tendência de crescimento natural" e, depois, por analogia, um processo de treinamento humano. Mas este último emprego, que implicava, habitualmente, cultura de alguma coisa, alterou-se, no século dezenove, no sentido de cultura como tal, bastante por si mesma. Veio a significar, de começo, "um estado geral ou disposição de espírito”, em relação estreita com a ideia de perfeição humana. Depois passou a corresponder a "estado geral de desenvolvimento intelectual no conjunto da sociedade". Mais tarde, correspondeu a "corpo geral das artes". Mais tarde ainda, ao final do século $[\mathrm{XX}]$, veio

8 Os conceitos de indústria, democracia, classe e arte extrapolam a etimologia ou a origem arcaica dessas palavras, eles evoluem concomitantemente com o período histórico no qual o conjunto de palavras passa a fazer parte do cotidiano social, assumindo inclusive diferentes significados, relacionando-o às suas origens e aos seus efeitos (Williams, 1969). 
a indicar "todo um sistema de vida, no seu aspecto material, intelectual e espiritual" (Williams, 1969, p. 18).

Hall (2006, pp. 134-136) confirma a problemática ao afirmar que o "conceito continua complexo - um local de interesses convergentes, em vez de uma ideia lógica ou conceitualmente clara. Essa 'riqueza' é uma área de contínua tensão e dificuldade no campo" e, utilizando suas conclusões, colabora com algumas características e maneiras de definir cultura que poderão, ou não, serem relacionais e/ou complementares: (i) "cultura não é uma prática; nem apenas a soma descritiva dos costumes e 'culturas populares' das sociedades"; (ii) perpassa, soma-se e se interrelaciona com todas as práticas sociais; (iii) "A cultura é esse padrão de organização, essas formas características de energia humana que podem ser descobertas como reveladoras de si mesmas [...] dentro ou subjacente a todas as demais práticas sociais"; por fim, (iv) propõe que, ao analisar a cultura, tenta-se descobrir "a natureza da organização que forma o complexo desses relacionamentos", "a descoberta de padrões característicos" por intermédio do estudo da organização geral em um caso particular (Hall, 2006, pp. 134-136).

Ao considerar as definições de cultura, obtémse como resultado que as manifestações culturais de um povo advêm da necessidade de explicitar suas crenças e rotinas mediante práticas sociais realizadas repetidamente por grupos pertencentes (ou não) a uma mesma sociedade, comunidade ou etnia que desenvolveram em conjunto os mesmos costumes ou hábitos, afim de garantir a sua permanência e, algumas vezes, instaurando como tradição essas atividades.

Integram o conceito de identidade (cultural) estabelecido entre as quatro categorias da hospitalidade urbana elencadas por Grinover (2016) as referências, tanto individuais quanto coletivas presentes em determinado grupo social ao compartilhar atitudes, crenças e celebrações como valores comuns.

Referenciando os bairros da cidade com forte identidade étnica, Bastos (2004, p. 263) conclui que ainda preservam festividades relacionadas às comunidades que lhes deram origem. "[...] No Bexiga, reduto dos italianos e negros, realizase o Nhoque da Sorte, o Maior Pão do Mundo e o Bolo de São Paulo, além da já citada festa da Achiropita, concentra-se uma das escolas de samba mais tradicionais da cidade, a Vai-Vai”, com exceção da primeira, todas as outras manifestações são realizadas na rua, espaço público do bairro.

Inventariadas nesse estudo durante os anos de 2015 e 2016, as manifestações culturais de diferentes relevâncias, cujo sucesso atrai moradores, visitantes e turistas, utilizando como critérios suas ocorrências no espaço público e limites do oficial bairro Bela Vista, foram relacionadas no Quadro 1 (organizadas em ordem cronológica). Salienta-se, porém, que fazem parte de um conjunto mais amplo, ou seja, o recorte utilizado nesse estudo não contempla a totalidade de manifestações que ocorrem no bairro.

Algumas ocorrem há mais de setenta anos, outras se restringiram à primeira edição em caráter experimental, ao passo que algumas possivelmente não venham mais a ocorrer, por motivos variados, seja pelo insucesso com o público ou pela ausência de apoio.

As dez manifestações culturais inventariadas foram numeradas e vinculadas à Figura 1. Com o intuito de expressar a sua diversidade foram sistematizadas as seguintes informações sobre cada uma: (i) nome da manifestação cultural, aquele utilizado publicamente como referencial; (ii) grupo étnico, indicando a percepção de predominância ou responsabilidade quanto ao seu surgimento e à manutenção; (iii) local, indicando a localização geográfica no bairro; (iv) ano de origem, com as indicações dos entrevistados ou fonte documental; (v) ocorrência, indicando a periodicidade da manifestação; (vi) data, para o dia(s) ou mês(es) em que o evento ocorre(u); (vii) finalidade, qual seu o objetivo principal/ inicial; (viii) dinâmica social, traz a percepção observada ou expressada pelos entrevistados sobre as manifestações; e (ix) participantes, público interveniente à manifestação. 
Quadro 1. Relação das manifestações culturais inventariadas e informações categoriais

\begin{tabular}{|c|c|c|c|c|c|c|c|c|c|c|}
\hline 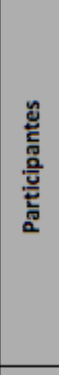 & 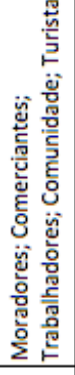 & 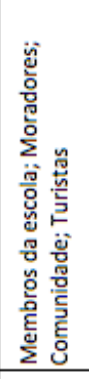 & 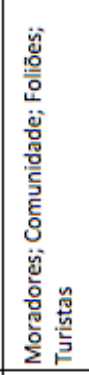 & 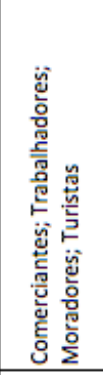 & 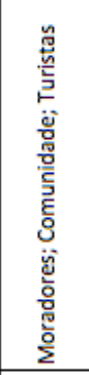 & 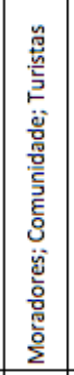 & 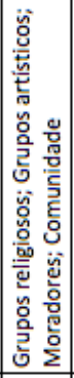 & 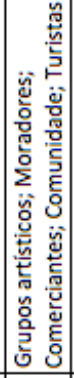 & 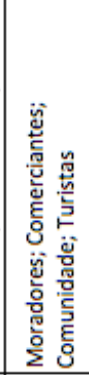 & 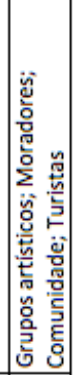 \\
\hline 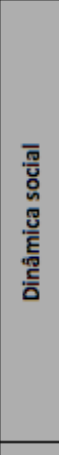 & 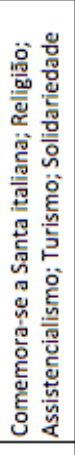 & 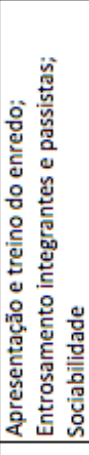 & 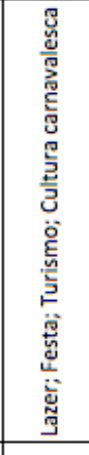 & 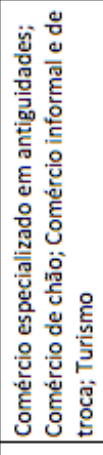 & 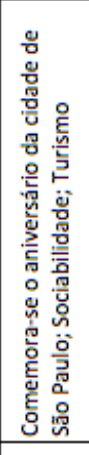 & 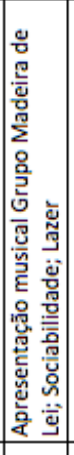 & 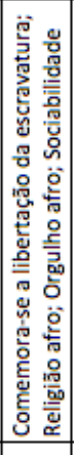 & 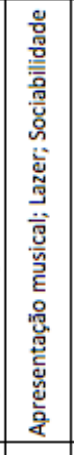 & 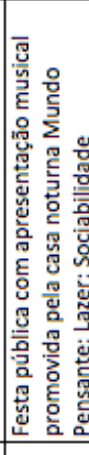 & 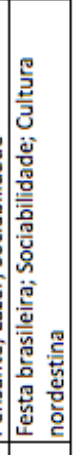 \\
\hline 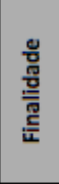 & 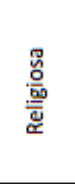 & 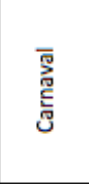 & 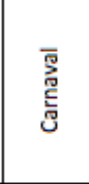 & 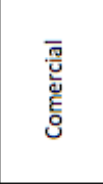 & 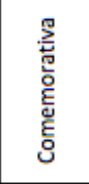 & 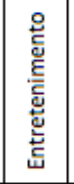 & 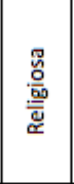 & 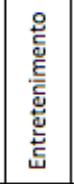 & 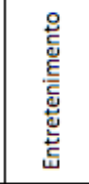 & 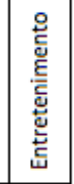 \\
\hline 罢 & 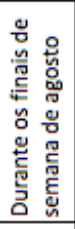 & 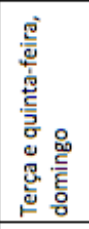 & 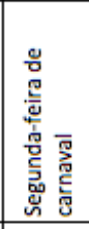 & 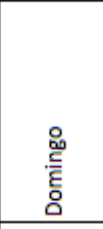 & 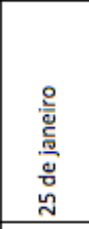 & 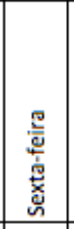 & 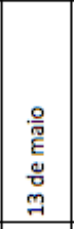 & 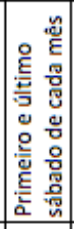 & 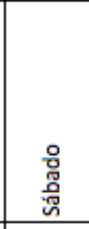 & $\frac{\circ}{\frac{8}{3}}$ \\
\hline 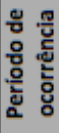 & $\begin{array}{l}\frac{\sqrt{3}}{3} \\
\frac{2}{4}\end{array}$ & 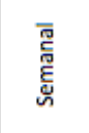 & $\begin{array}{l}\frac{\overline{3}}{3} \\
\frac{2}{4}\end{array}$ & 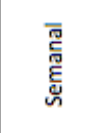 & $\begin{array}{l}\frac{\overline{3}}{3} \\
\frac{2}{4}\end{array}$ & 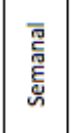 & $\begin{array}{l}\sqrt{3} \\
\bar{z} \\
\end{array}$ & 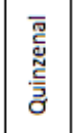 & 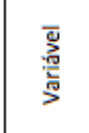 & $\begin{array}{l}\frac{7}{3} \\
\frac{3}{4}\end{array}$ \\
\hline$E$ & 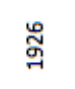 & 号 & 票 & $\stackrel{\widetilde{g}}{\mathfrak{g}}$ & 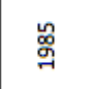 & 울 & ڤ̆ & 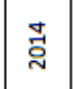 & 芫 & 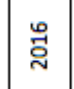 \\
\hline$\overline{\mathrm{g}}$ & 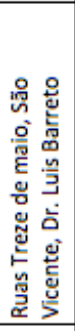 & 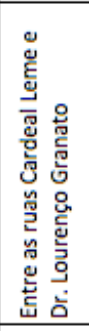 & 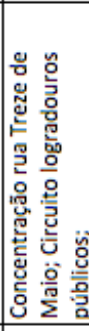 & 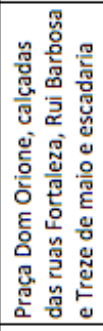 & 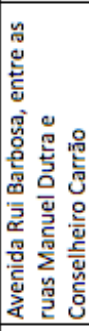 & 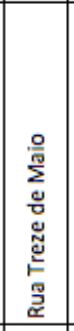 & 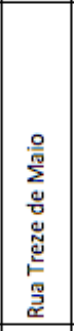 & 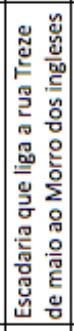 & 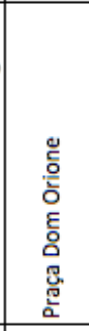 & 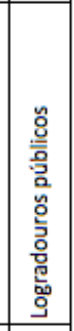 \\
\hline 胥 & 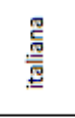 & 윰 & 苦 & 蒡 & 蒂 & 蒡 & 옴 & 莒 & 蒡 & 蔙 \\
\hline 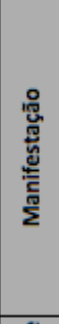 & 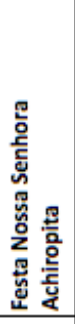 & 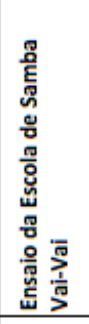 & 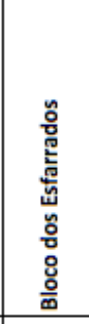 & 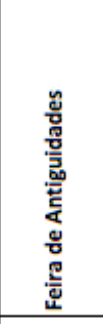 & 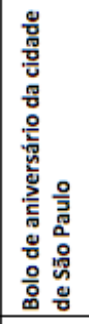 & 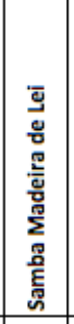 & 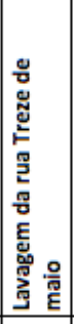 & $\begin{array}{l}\pi \\
0 \\
0 \\
0 \\
0\end{array}$ & 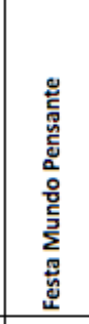 & 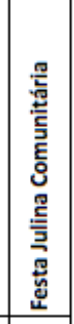 \\
\hline $\begin{array}{l}\frac{\tilde{g}}{\bar{z}} \\
\underline{\underline{c}}\end{array}$ & न & N & $\mathrm{m}$ & J & in & 0 & r & $\infty$ & $\sigma$ & 요 \\
\hline
\end{tabular}

Fonte: Os autores (2017). 
Figura 1: Identificação dos locais onde ocorrem as manifestações culturais inventariadas

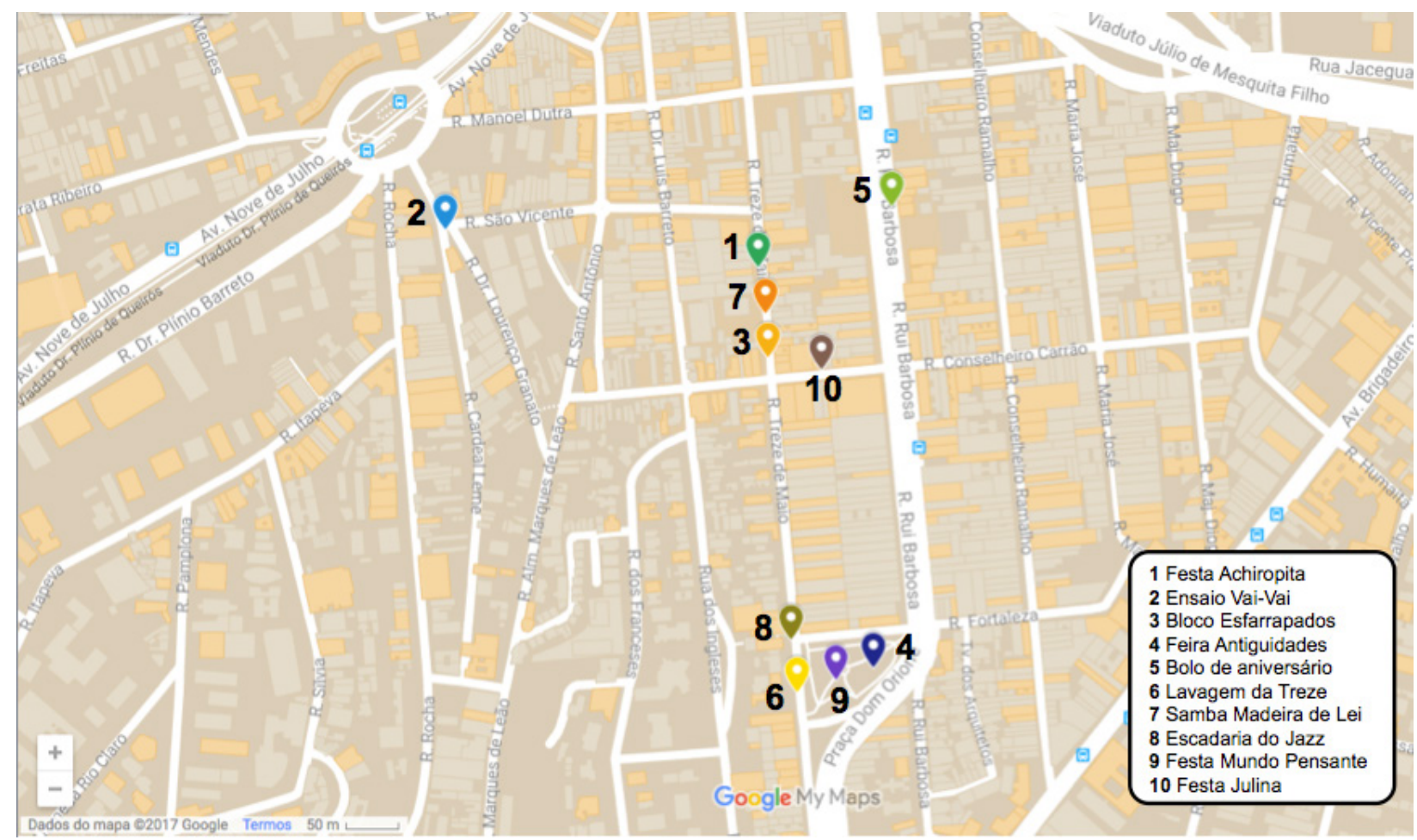

Fonte: Os autores (2017).

Ao visualizar a Figura 1, revela-se a ocorrência das atividades em uma área geográfica relativamente limitadora, precisamente as manifestações culturais estão concentradas ao longo da Rua Treze de Maio, o que denota a centralidade e a importância da via para o bairro, como exceção se observa a manifestação cultural de número 2, relativa ao ensaio da Escola de Samba Vai-Vai, que surgiu e permaneceu na (antiga) região de várzea do Rio Saracura, originalmente ocupada por negros.

A primeira das manifestações culturais, a Festa da Nossa Senhora Achiropita, padroeira italiana da região de Rossano, sul da Itália, é talvez a mais tradicional e importante para o bairro, em decorrência do expressivo contingente de pessoas comprometidas com o evento (aproximadamente trezentos voluntários), agregando a equipe organizadora, que envolve desde a coleta de doações, a produção e a comercialização de um grande volume de alimentos até o número de visitantes, que na $89^{a}$ edição (2016) foi estimado em 20.000 pessoas por noite (totalizando 160.000 frequentadores ao longo dos quatro finais de semana do mês de agosto).

De finalidade religiosa, o início da Festa da Achiropita é datado no ano de 1926, quando somente a imagem era exposta na Rua Treze de
Maio para adoração dos fiéis. Com a recorrência da manifestação, o formato foi evoluindo para o de uma grande quermesse, envolvendo a comunidade, ocupando três ruas do bairro durante os finais de semana do mês de agosto, servindo diversas iguarias produzidas pelo voluntariado da paróquia e promovendo o retorno dos valores arrecadados em prol de serviços assistenciais organizados pela igreja.

O Ensaio da Escola de Samba Vai-Vai, identificada como a segunda manifestação cultural mais antiga do Bexiga, surgiu a partir da ocupação do contingente negro, datada desde antes da divisão das antigas chácaras em lotes (anterior ao século XIX) e da formação do território como bairro. Historicamente, nesse mesmo território, a origem da Escola Vai-Vai partiu do time de futebol de várzea desses moradores. Ressalta-se que os ensaios oficiais ocorrem no entroncamento de três ruas, ou seja, no espaço público do bairro, e começam sempre no segundo semestre do ano e chegam a ocupar três dias da semana (terças, quintas e domingos).

Durante o carnaval, outra manifestação notável quanto à durabilidade e à popularidade é o Bloco dos Esfarrapados, que inicia a concentração com os foliões em frente à Igreja da Nossa Senhora Achiropita, à Rua Treze de Maio sempre às $10 \mathrm{~h}$ da 
segunda-feira, desde 1947. Firma-se como o bloco carnavalesco mais antigo da cidade de São Paulo e, ao juntar os foliões, percorre as ruas dos bairro, animado pelos trios elétricos, artistas do bairro e/ou componentes da bateria da Escola de Samba Vai-Vai.

Por meio da Sociedade em Defesa e Progresso da Bela Vista (Sodepro), comerciantes do bairro se organizaram para promover a Feira de Antiguidades do Bexiga, que acontece todos os domingos desde 1982, na principal praça do bairro, a Dom Orione, localizada entre as ruas Treze de Maio e Rui Barbosa. A prática da feira endossa o comércio fixo de móveis usados e antiguidades, agregando mais essa faceta ao bairro. Cerca de 100 expositores fixos organizam objetos e itens usados e de interesses específicos para exposição e venda em barracas, a compra ou a troca também são ali práticas comerciais comuns. Enriquece o comércio uma grande movimentação de outros vendedores "informais" que ocupam tanto o largo da Escadaria, localizada em frente à Praça Dom Orione e que liga o Bexiga ao Morro dos Ingleses, quanto as calçadas, ao longo do quadrilátero marcados pelas ruas Treze de Maio, Fortaleza, Conselheiro Carrão e Rui Barbosa.

Desde a década de 1980 a comemoração do aniversário da cidade de São Paulo, em 25 de janeiro, encontrou no Bexiga a principal festa. Desde a primeira versão, bolos de formatos cada vez maiores foram organizados e montados na Avenida Rui Barbosa, cujo clímax é a distribuição gratuita do bolo. Com a permanência, a prática de novas edições, apoio e divulgação nos meios de comunicação, a celebração trouxe visibilidade para o bairro, atraindo também visitantes e turistas.

O Samba do Grupo Madeira de Lei (também conhecido como Samba do Bexiga) ocorre gratuitamente todas as sextas-feiras a partir das $19 \mathrm{~h} \mathrm{em}$ frente à Igreja Nossa Senhora Achiropita. O grupo, formado há 40 anos, se apresenta na calçada localizada à Rua Treze de Maio desde 2010, enquanto que os frequentadores se posicionam e "fecham" a via para a participação.

A Lavagem da Rua Treze de Maio é a manifestação que promove a religião e a cultura dos negros, haja vista sua ocupação inicial do bairro. Realizada sempre no dia 13 de maio, a prática começou em 2013 e é regida por praticantes das religiões afro-brasileiras, como o candomblé e a umbanda, que buscam trazer visibilidade à data ${ }^{9}$. Organizado pelo grupo/bloco musical Ilu

9 Dia 13 de maio de 1888: data da sanção da Lei Áurea que finalizou o processo de abolição no Brasil.
Obá de Min - nome que em Yorubá significa "mãos femininas que tocam tambor para Xangô" -, é também referência da cultura negra na cidade de São Paulo, estimulando o empoderamento feminino e as questões raciais.

Em 2014 o evento Escadaria do Jazz, organizado por um grupo de comerciantes, representantes culturais e moradores do bairro com o apoio da Prefeitura Municipal de São Paulo, ocupou com músicos o bem tombado, que liga o Bexiga ao Morro dos Ingleses. Passaram então a se apresentar mensalmente (sempre no segundo sábado de cada mês) bandas convidadas pelos organizadores, atraindo outros públicos, bem como atribuindo um novo uso para esse espaço público do bairro. O evento conjuga-se com o festival promovido pelo empreendimento cultural Mundo Pensante, sediado no bairro e que expandiu suas atividades em 2016 para a Praça Dom Orione, promovendo, além das apresentações musicais, uma feira alternativa de artes, alimentos e bebidas. Tal manifestação cultural não apresenta periodicidade definida e ocorreu apenas uma vez no período temporal da pesquisa.

A última manifestação cultural listada e observada ocorreu pela primeira em julho de 2016 na Rua Conselheiro Carrão (entre as ruas Treze de Maio e Rui Barbosa), que foi fechada para a circulação de carros. De acesso livre, agrega a cultura junina marcadamente presente no contingente nordestino do bairro.

O surgimento das manifestações culturais no bairro do Bexiga é dinâmico - ao considerar que existem várias frentes e grupos que as promovem - e o inventário não revela a sua totalidade, no entanto reforça seu potencial em acolher outras manifestações que possam se desenvolver nesse território.

\section{DISCUSSÃO DOS DADOS}

Para tratar as manifestações culturais escalonando-as com as categorias de hospitalidade urbana apresentadas, optou-se pelo uso de uma escala Likert ${ }^{10}$. Fundamentado nos conceitos, na experiência de campo e observação, foram associadas em cada uma das categorias os valores: igual a 1 (um) para "Não Atende"; igual a 2 (dois) para "Atende Parcialmente"; e valor 3 (três) associado ao item que "Atende Totalmente".

10 Escala de resposta psicométrica, cujo respondente tem a possibilidade na definição dos níveis de concordância. 
No Gráfico 1 são apresentadas as avaliações realizadas em cada uma das manifestações culturais, de forma que seja possível visualizar o grau de atendimento de cada uma das categorias elencadas para tal análise, ordenadas a partir daquelas com maior pontuação.

Gráfico 1: Representação gráfica da avaliação das categorias de hospitalidade urbana analisadas nas manifestações culturais

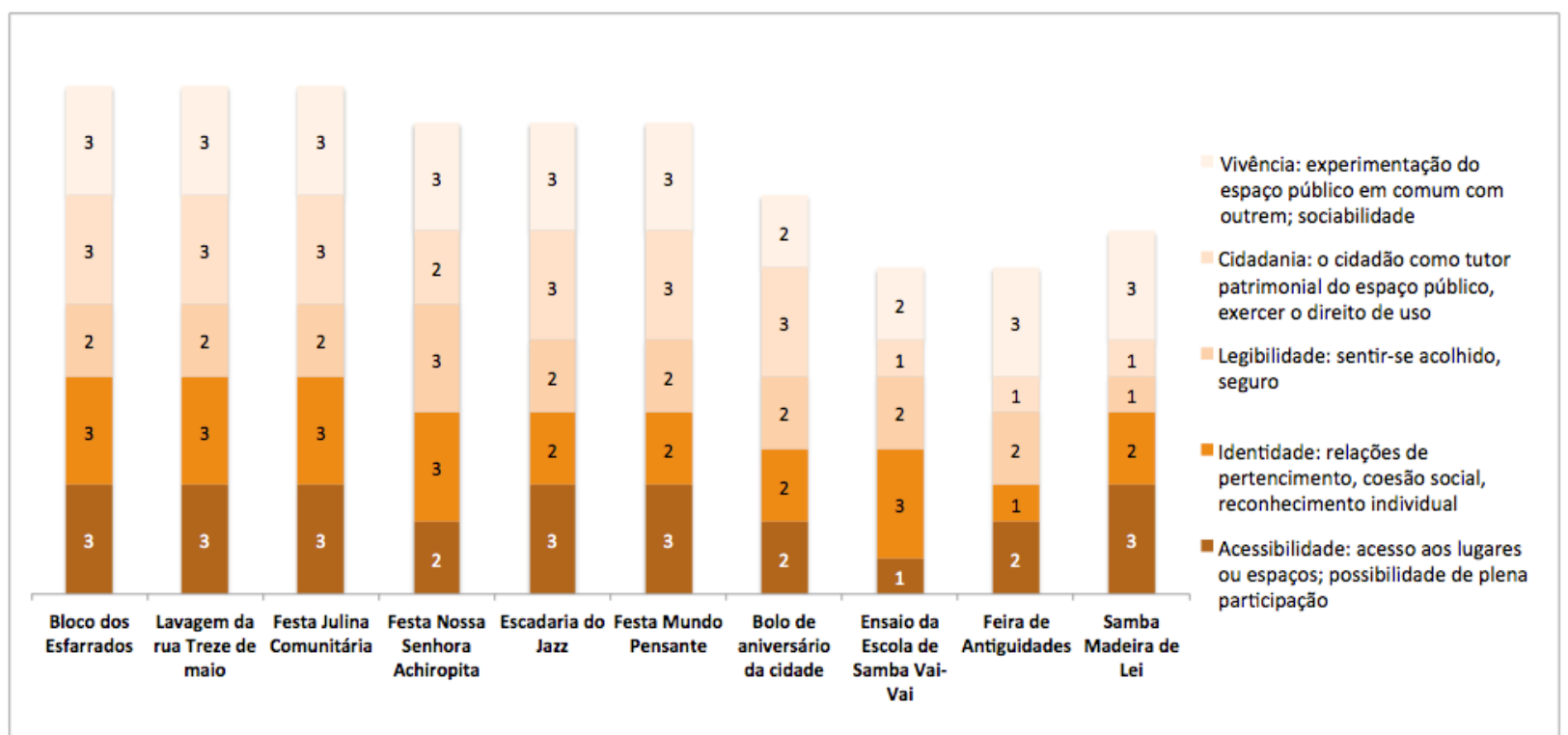

Fonte: Os autores (2017).

A discussão prioriza os valores iguais a um, ou seja, que "não atende" aos conceitos das categorias, sobretudo que não foram percebidos nas manifestações culturais observadas, cuja proposta é refletir sobre os objetos de estudo - o corpus da pesquisa - sob a ótica do pesquisador, fundamentada pelo referencial teórico apresentado e discutido, em um total de três manifestações, nas categorias de cidadania (Ensaio da Vai-Vai, Samba Madeira de Lei e Feira de Antiguidades), de legibilidade (Samba Madeira de Lei) e identidade (Feira de Antiguidades).

\section{CIDADANIA}

Sob o fundamento da cidadania como garantia de direitos dos indivíduos quanto ao uso da cidade, identificou-se a condição distinta da Feira de Antiguidades frente às demais manifestações culturais, principalmente em virtude de seu caráter comercial, fato que acarreta a restrição à liberdade de circulação (ir e vir). Grinover (2016, p. 209) expressa que "A cidadania vive e respira no espaço público [...], é o lugar onde as vontades 'aparecem' e se entrelaçam com outras vontades, produzindo um mundo comum".

Em decorrência da presença dos expositores e objetos ofertados, a fruição junto aos espaços e aos equipamentos de lazer: a Praça Dom Orione e a Escadaria do Bexiga são substancialmente impactadas, bem como a locomoção nas calçadas do entorno, ocupadas pelo "comércio de chão" em decorrência da atratividade econômica da feira.

\section{ACESSIBILIDADE}

Embora de configuração diferente das demais manifestações, o Ensaio da Vai-Vai restringe o uso das vias onde ocorre, prática que não afeta diretamente os espaços de convívio e lazer do bairro, mas acrescenta o fator econômico na avaliação ao considerar o ingresso pago ao espaço onde a manifestação ocorre - esse cercado, limitado -, fica então caracterizado como espaço "privado", fato que restringe a participação e acesso plenos.

Sobretudo a manifestação beneficia a comunidade, seja em sua dimensão ao atrair visitantes e agregar valor econômico ao comércio local, seja com os projetos sociais promovidos pela Escola de Samba Vai-Vai para o público infantil da comunidade, que direciona a pensar na cidadania como identidade compartilhada, praticada na hospitalidade, ofertando abrigo, alimentação e afeto (Grinover, 2016). 


\section{LEGIBILIDADE}

Nessa categoria, destaca-se o Samba Madeira de Lei, ao não atender completamente características da legibilidade, pois embora festivo e altamente acessível por ser livre e gratuito para todos os públicos, seu formato não oferece acolhimento e tampouco segurança, haja vista a improvisação de como ocorre, fato esse talvez decorrente da espontaneidade da manifestação. Contrariando as posições de Raffestin (2008) e Calliari (2016) quanto à segurança que o espaço público da cidade deve oferecer, os participantes (hóspedes/convidados/visitantes) permanecem à própria sorte ao disputar o espaço da rua com os carros nas noites de sexta-feira, uma vez que não é interditada ao uso de automóveis e ao mesmo tempo sendo a via onde se concentra a maioria dos atrativos do bairro (bares, restaurantes e casas noturnas).

\section{IDENTIDADE}

Partindo do pressuposto que "As identidades fundamentam-se em dados reais e objetivos, recolhidos de traços, hábitos [...]" (Grinover, 2016, p. 220), a ausência desse aspecto foi percebida na Feira de Antiguidades, ao passo que um dos indicadores que suporta a classificação é, de maneira geral, a inassiduidade e não participação direta dos moradores na feira. Notou-se que o público principal é aquele que, atraído pelos restaurantes e cantinas do Bexiga, aproveitam o passeio pré ou pós-almoço.

Outra prática que pode endossar a ausência de identidade é que mesmo os expositores especializados que ocupam as barracas fixas da feira também não são do bairro, são vendedores especializados cuja presença atrai um contingente segmentado de clientes. Logo, a permanência desse público, além de temporária, segue a diretriz do comércio, cujo objetivo principal é mercantil, estabelecendo pouco ou nenhum vínculo com o entorno ou o território ocupado.

\section{CONSIDERAÇÕES FINAIS}

A identidade cultural refere-se às representações individuais e coletivas presentes em determinado grupo social que compartilha atitudes, crenças e valores comuns. São as características de um povo, apresentadas pela sua forma peculiar de pensar, agir, falar e, ainda, as representações simbólicas geradas por intermédio da vivência entre eles. Posto isso, a cultura é também o efeito das opções e das práticas do ser humano para ordenar e dar sentido à vida em sociedade entre suas inúmeras escolhas.

As manifestações culturais que ocorrem na cidade passam a ser compreendidas como necessidade de sociabilidade e/ou fruto do acolhimento entre seus sujeitos, que desencadeia na percepção do "espaço público como 'lócus' de uma cultura urbana compartilhada, fundada em valores coletivos, uma cultura que envolve o convívio com os opostos, envolve diversidade, trocas e, mais do que tudo, o desfrute de uma cidade que tenha espaço urbano como panorama de fundo ativo" (Grinover, 2013, p. 20). Compreende-se então que o território do Bexiga tem papel agregador na cultura urbana da cidade de São Paulo, ao envolver desde o acolhimento inicial de diferentes conjuntos sociais - sejam eles de diferentes etnias, culturas, costumes ou classes econômicas - até a promoção da sociabilidade resultante da (con)vivência entre tais sujeitos.

Além de características comuns como o pouco tempo de origem, a gratuidade e/ou o amplo espaço da rua como cenário, algumas das manifestações culturais são também apoiadas por grupos com identidades definidas, atraem número satisfatório de participantes, apoiadas na proposição de cunho identitário brasileiro das culturas carnavalesca, religiosa, afro, caipira, etc.

Questões como "quem é o anfitrião urbano?" podem surgir, todavia de resposta complexa, vê-se de um lado a administração pública que eventualmente se esforça (ou não) para provocar a hospitalidade na cidade por meio de inúmeras ações, por outro, os moradores-cidadãos, ao apoiar, criar ou desenvolver as manifestações culturais como elemento-chave e agregador de participação no cotidiano da cidade. Portanto, acredita-se que, independente do grau de hospitalidade urbana apresentado por cada uma das manifestações culturais ou do espaço/território onde ocorrem, essas assumem características que objetivam e potencializam as práticas sociais como ferramentas promotoras da hospitalidade na cidade.

Por fim, como contribuição, apresenta-se um instrumento metodológico, cujo objetivo é a aplicação prática das categorias propostas (fato que não limita a inclusão ou a exclusão), por 
meio da pesquisa de campo e principalmente da observação do espaço urbano, justificada pela validação apresentada nesse artigo.

\section{REFERÊNCIAS}

Bell, David. (2007). Hospitality and urban regeneration. In: Lashley, Conrad, Lynch, Paul e Morrison, Alison. (orgs.). Hospitality: A social lens, pp. 89-100.

Bastos, Sênia. (2004). Nosso Patrimônio Cultural: uma metodologia de pesquisa. PASOS Revista de Turismo y Patrimonio Cultural. v. 2, n. 2, pp. 257-265.

Bastos, Sênia Regina, Rameh, Ladjane Milfont, \& Bitelli, Fábio Molinari. (2016). O conceito de hospitalidade de Jacques Derrida nos artigos científicos do Portal de Periódicos da Capes. Anais XIII Seminário ANPTUR, v. 13.

Camargo, Luiz Octávio de Lima. (2003). Os domínios da hospitalidade. Dencker, A. D. F. M., \& Bueno, M. S. (orgs.). Hospitalidade: cenários e oportunidades. São Paulo: Pioneira Thomson Learning, 7-28.

Derrida, Jacques, \& Dufourmantelle, Anne. (2003). Anne Dufourmantelle convida Jacques Derrida a falar da hospitalidade. Trad. Antonio Romane. São Paulo: Escuta, 2003.

Félix, W. J. S., Ipiranga, A. S. R., Câmara, J. F., \& Rodrigues, K. M. (2008). De "Tapera" ao turismo: quando organizações transformam cidades. TurismoVisão e Ação, 10(3), 335-357.

Grinover, Lúcio. (2009). A hospitalidade na perspectiva do espaço urbano. Revista Hospitalidade, v. 6, n. 1, pp. 4-16.

Grinover, Lúcio. (2013). Hospitalidade, qualidade de vida, cidadania, urbanidade: novas e velhas categorias para a compreensão da hospitalidade urbana. RITUR - Revista Iberoamericana de Turismo, v. 3, n.1, pp. 16-24.

Grinover, Lúcio. (2016). A cidade à procura da hospitalidade. São Paulo: Aleph.

Hall, Stuart. (2006). Da diáspora: identidades e mediações culturais. Belo Horizonte: Editora UFMG.

Lashley, Conrad \& Morrison, Alison (orgs.). (2004). Em busca da hospitalidade: perspectivas para um mundo globalizado. Barueri, SP: Manole.

Nogueira, André Martins. (2015). High Line Park e Elevado Costa e Silva: Abordagem Similar, Realidades Distintas. Revista Nacional de Gerenciamento de Cidades, v. 3, n. 21.

Raffestin, Claude (2008). Réinventer l'hospitalité. Communications. Paris: Editions du Seuil, n. 65, p. 165-174, 1997. Tradução: Maryelis Siqueira Bueno.

São Paulo, Prefeitura Municipal de. (2015). Moradores decidem quais ruas poderão ser abertas para ciclistas e pedestres em seus bairros. 20/09/2015. Disponível em: $\quad$ http://www.capital.sp.gov.br/noticia/moradoresdecidem-quais-ruas-poderao-ser-abertas. Consultado em $27 / 07 / 2017$
Severini, Valéria Ferraz. (2014). Hospitalidade urbana: ampliando o conceito. RITUR - Revista Iberoamericana de Turismo, v. 3, n. 2, pp. 84-99.

Williams, Raymond. (1969). Cultura e Sociedade: 17801950. São Paulo: Editora Nacional.

\section{Contribuições dos autores na construção deste artigo:}

Fábio Molinari Bitelli: Pesquisa de campo e bibliográfica, coleta de dados, produção de texto e gráficos.

Sênia Regina Bastos: Orientação, produção de texto e revisão. 